Revista Brasileira de Cartografia

ISSN 1808-0936 | https://doi.org/10.14393/revbrascartogr

Sociedade Brasileira de Cartografia, Geodésia, Fotogrametria e Sensoriamento Remoto

\title{
A Evolução do Ensino de Topografia e Áreas Afins na Escola Politécnica da Universidade de São Paulo
}

\author{
The Evolution of Teaching Geomatics at the Polytechnic School of University of São Paulo
}

\author{
Jhonnes Alberto Vaz ${ }^{1}$, Jorge Pimentel Cintra ${ }^{2}$, Flávio Guilherme Vaz de Almeida Filho ${ }^{3}$ \\ 1 Universidade de São Paulo, Departamento de Engenharia de Transportes, São Paulo, Brasil. jhonnes.vaz@usp.br \\ Universidade Católica de Santos, Centro de Ciências Exatas Arquitetura e Engenharia, Santos, Brasil. \\ ORCID: https://orcid.org/0000-0003-4503-2711 \\ 2 Universidade de São Paulo, Museu Paulista da USP, DAC, São Paulo, Brasil. jpcintra@usp.br \\ ORCID: https://orcid.org/0000-0002-1369-6110 \\ 3 Universidade de São Paulo, Departamento de Engenharia de Transportes, São Paulo, SP, Brasil. flaviovaz@usp.br \\ ORCID: https://orcid.org/0000-0002-8111-3204
}

Resumo: A determinação da posição relativa de pontos e a representação gráfica da superfície terrestre entre outros conhecimentos de Topografia e ciências afins está presente em diferentes momentos do exercício profissional de engenheiros civis e de outras modalidades. Na Escola Politécnica da Universidade de São Paulo (EPUSP) o ensino da área acontece desde a fundação da Escola no final do Século XIX. Ao longo desse período de mais de um século de ensino de Topografia e ciências afins na EPUSP ocorreram diversas alterações que impulsionaram mudanças na estrutura da Escola e da Universidade, na Educação Superior e no contexto social e político gerando novas necessidades e demandas da sociedade, exigindo que engenheiros e profissionais da área da Topografia se adaptassem às novas demandas e possibilidades. Frente a essas evoluções surgiu a Geomática que engloba a Topografia e áreas afins na era da tecnologia e da informática. Para o ensino da Geomática há o constante desafio da adequação e adaptação às evoluções e mudanças. Desta forma, o objetivo deste trabalho é apresentar e discutir a evolução do ensino de Topografia na EPUSP frente às mudanças e evoluções científicas, metodológicas e tecnológicas. Em um momento em que as mudanças e inovações no mundo ocorrem em ritmo cada vez mais acelerado, há a necessidade da discussão sobre o ensino e a utilização das tecnologias e adaptação às mudanças e evoluções pautada e embasada pelo ensino fundamentado na valorização dos conceitos permanentes, frentes à tecnologia em constante mudança.

Palavras-chave: Ensino Superior. Tecnologia. Topografia. Geomática. Inovação.

\begin{abstract}
The determination of relative position of points and the graphical representation of the Earth's surface, among other knowledge of Land Survey and related Sciences, is present at different moments in the professional practice of civil engineers. At the Polytechnic School of the University of São Paulo (EPUSP), teaching Land Survey has been taking place since the School's Foundation in the late 19th century. After this period of more than a century of teaching survey at EPUSP, scientific, methodological, and technological developments have occurred. These developments drove changes in the structure of the School and the University, in Higher Education and in the social and political context, generating new needs and demands from society, requiring engineers and surveyors to adapt to the new demands and possibilities. Facing these evolutions came Geomatics, which includes Land Survey and related areas in the era of technology and information technology. For the teaching of Geomatics, there is a constant challenge of adapting to evolutions and changes. Thus, the objective of this work is to present and discuss the evolution of Land Survey teaching at EPUSP, in the face of scientific, methodological, and technological changes and evolutions. At a time when changes and innovations in the world occur at an increasingly accelerated pace, there is a need for discussion about teaching and the use of technologies and fit to changes and evolutions ruled on teaching based on the importance of permanent concepts facing constantly changing technology.
\end{abstract}

Keywords: Higher Education. Technology. Land Survey. Geomatics. Innovation.

\section{INTRODUÇÃO}

A Topografia teve um importante papel na elaboração de mapas do território e no desenvolvimento da Engenharia brasileira. A Escola Politécnica da Universidade de São Paulo (EPUSP), desde a sua fundação em 
1893, procurou estar na vanguarda do desenvolvimento da Engenharia e da formação de engenheiros.

O ensino de Topografia nessa escola esteve presente desde o início, passando por diversos regimes e políticas educacionais. A Escola Politécnica, junto com a Faculdade de Direito e a Faculdade de Medicina, se integraram para a fundação da Universidade de São Paulo (USP) em 1934. Adaptou-se aos novos modelos universitários, principalmente após as mudanças originadas pelas reformas acontecidas na ditadura Vargas e na reforma universitária de 1968 e posteriormente pelas mudanças das estruturas curriculares (EC) 1, 2 e 3 (LOSCHIAVO DOS SANTOS, 1985; BALBO, 017); BRAGGIO, 2019).

Adaptou-se, também, às mudanças da ciência e a da tecnologia topográfica que ocorreram durante esse período. $\mathrm{Na}$ área da Topografia, diversos avanços aconteceram em equipamentos de campo, recursos de pré e pós processamento dos dados e desenho topográfico. A Escola soube conciliar tradição e modernidade, dando ênfase aos conceitos e métodos permanentes frente à mutabilidade dos equipamentos e técnicas concretas.

No final do Século XIX, a Topografia era realizada através de levantamentos com taqueômetros, teodolitos, níveis, correntes e fitas, com largo emprego de equipamento de tipo analógico (óptico-mecânicos), únicos existentes à época. Os principais trabalhos estavam ligados a levantamentos para a construção de estradas de ferro, loteamentos, mapas e levantamento de coordenadas do território. Completavam-se, portanto, com medições astronômicas e geodésicas, também ensinadas na Escola, com caráter prático (CINTRA, 1993).

Durante a primeira metade do Século XX, os equipamentos ópticos-mecânicos, como os níveis e teodolitos, evoluíram gradualmente em precisão, processos de instalação e leitura, tamanho e peso. As correntes de agrimensor evoluíram para as fitas e trenas. Novas técnicas e processos surgiram e se consolidaram, como a aerofotogrametria, o uso de projeções cartográficas, destacando-se a Universal Transversa de Mercator (UTM) para uso em projetos de engenharia. Também ocorreram evoluções no conhecimento e determinação da superfície geoidal e caracterização do elipsoide (WOLF, 2002).

No último quarto do Século XX ocorreu a popularização da informática, da eletrônica e da computação gráfica. Surgem instrumentos eletrônicos como o Teodolito Eletrônico e os Medidor Eletrônico de Distância, que integrando-se deram origem à Estação Total. Esta, além de medir ângulos e distância em um único instrumento, permite armazenar os dados através de uma caderneta eletrônica de campo e, em seguida, processar automaticamente esses dados em computadores. Também se popularizaram os computadores pessoais, programas de cálculo, processamento de dados e desenho assistido por computador (CAD Computer Aided Design), evoluindo para programas diretamente aplicados à Topografia (Modelagem digital de terreno, banco de dados), com interface para programas voltados para o Projeto de vias.

Já no final do Século XX e início do XXI novas metodologias, tecnologias e ciências surgiram e se consolidaram, como por exemplo o Sistema Global de Navegação por Satélite (GNSS - Global Navigation Satellite System), Sensoriamento Remoto, Nível Digital, Sistemas de Varredura a Laser terrestre e aerotransportado, Aeronaves Remotamente Pilotadas (RPA - Remotely Piloted Aircraft) ou VANT (Veículos Aéreos Não Tripulado). Esses novos recursos permitiram maior agilidade, menor tempo de processamento, através da automação de processos, além de permitir trabalhar com maior volume de dados e informações (SILVA, 2020).

No campo do ensino as mudanças aconteceram em paralelo. Além da lousa e do giz, passou-se para as projeções em transparência e a seguir aos computadores, permitindo as projeções digitais e aulas em laboratório de informática: ou seja, novas ferramentas educacionais para o ensino da disciplina.

Este trabalho tem como objetivo apresentar e discutir a evolução da Topografia e de seu Ensino a partir da compreensão evolutiva do Ensino da Topografia e disciplinas afins na Escola Politécnica da USP, desde a sua fundação até o final da segunda década do Século XXI. Pretende discutir e compreender as mudanças e impactos que os avanços tecnológico e científico, ao longo deste período, proporcionaram na área da Topografia e de seu ensino, bem como analisar as contribuições para essa área, no Estado e no país, levando em conta a graduação e, principalmente, o Programa de Pós-Graduação em Engenharia de Transportes, olhando para na Linha de Pesquisa em Informações Espaciais com ênfase em Topografia, Geodesia e Cartografia.

Por fim, visa analisar o processo didático, que passou a valorizar mais os conceitos do que as técnicas 
concretas de operação de equipamentos na formação de Engenheiros de diversas modalidades. A ênfase nos aspectos conceituais não implica ou exclui o olhar para as técnicas, para os instrumentos e seus avanços tecnológicos. Assim, o que se defende, frente ao crescimento das tecnologias e conteúdos e a diminuição da carga horária, é a focalização em conceitos, menos sujeitos à mutação.

\section{O ENSINO DE TOPOGRAFIA NA ESCOLA POLITÉCNICA DA UNIVERSIDADE DE SÃO PAULO}

A EPUSP, desde a sua fundação, procurou acompanhar as demandas da sociedade, o aprimoramento das ciências e das tecnologias, mantendo seu protagonismo e vanguardismo na formação de engenheiros. Ao longo deste mais de um século de história, como se apontou, o ensino da Topografia esteve presente e transformou-se ao longo do tempo sofrendo impactos das evoluções científica, metodológicas e tecnológicas da área e das mudanças internas institucionais. Este item apresenta de forma sintetizada essas mudanças e a evolução da disciplina de Topografia na EPUSP. Por fim busca estabelecer uma conexão entre as evoluções através de sua análise em uma linha do tempo.

\subsection{Avanços Científicos, Metodológicos e Tecnológicos na Topografia}

Define-se Topografia como "a ciência aplicada que estuda os métodos de representar um terreno (uma parte da superfície da Terra) para fins de projeto" (CINTRA, 2012). Esta é uma definição mais prática da Topografia, que versa sobre sua aplicação na área da Engenharia.

No entanto, a Topografia, a Engenharia e o mundo evoluíram. As necessidades da sociedade também, tornando-se mais desafiadoras e implicando soluções mais complexas, interdisciplinares e integradoras. Nesse sentido criou-se a área da Geomática para abarcar diversas áreas do conhecimento do espaço terrestre, como por exemplo a Topografia, a Geodésia, a Cartografia, e a informática aplicada a elas.

Quando da fundação da EPUSP a Topografia estava baseada em levantamentos com taqueômetros, trânsitos, teodolitos e níveis óptico-mecânicos. Em áreas afins da Topografia, como por exemplo a Geodésia, o final do Século XIX foi um momento de importantes avanços conceituais que possibilitariam posteriormente o desenvolvimento de diversas tecnologias, principalmente aquelas que utilizam a radiação eletromagnética REM. Também foi um período de consolidação da profissão de geodesista e com as contribuições de Gauss e Helmert (IHDE; REINHOLD, 2017).

No Brasil, mais especificamente em São Paulo, o final do Século XIX foi um momento de início do crescimento demográfico em função da imigração, do desenvolvimento industrial na capital paulista e de expansão da agricultura com a consequente ocupação do território. Obras de infraestrutura, principalmente a construção de estradas de ferro que ligavam o interior paulista à capital e ao Porto de Santos, visando a exportação de café, tinham os levantamentos topográficos como base para a sua execução (CAMPOS, 2007; CAMPOS; GITAHY, 2009; PADILHA, 2010).

Foi nesse cenário que a Escola Politécnica foi fundada, com uma visão da aplicação prática da Engenharia para impulsionar o desenvolvimento, baseado na filosofia das Escolas Politécnicas alemãs (ETH Eidgenössische Technische Hochschule), essencialmente aplicada, em contraposição à Escola Politécnica de Paris, modelo da Politécnica do Rio de Janeiro.

No momento de sua fundação, a Escola contava com equipamentos modernos para a época: teodolitos, taqueômetros, trânsitos e níveis que eram utilizados em aulas práticas das cadeiras de Topografia, Geodesia e Astronomia de campo. No ano seguinte ao da inauguração da Escola, seu fundador, Antônio Francisco de Paula Souza, publicou o livro "Elementos de Taqueometria: cleps, descrição e uso prático deste instrumento" (SOUZA, 1895).

No início do Século XX as evoluções continuaram no mesmo ritmo do final do século anterior, surgindo algumas ideias, ainda no campo das teorias e conceitos, que viriam a ser desenvolvidas no decorrer do Século XX e início do Século XXI.

Grandes mudanças e evoluções da Topografia e ciências afins, bem como em todo o campo da Engenharia, ocorreram durante as duas grandes guerras, com a indústria bélica buscando soluções para 
melhorar a qualidade e a velocidade de obtenção de informações sobre a superfície terrestre, bem como determinar a posição e facilitar a navegação (HARTCUP, 2000). Ocorreram evoluções nas áreas da aerofotogrametria, utilização da REM em medições de distâncias, emprego de projeções cartográficas e referenciais. No que diz respeito aos instrumentos topográficos estes passaram a ficar cada vez mais portáteis, com dispositivos que proporcionavam rapidez em sua utilização e aumento da precisão dos dados obtidos em campo, com grande destaque para fabricantes alemães e suíços como a Wild, Kern e Zeiss. A EPUSP dispunha de teodolitos desses fabricantes; porém nessa época, o instrumento mais utilizado para as aulas e trabalhos de campo era o Teodolito Keuffel \& Esser, de origem americana (MANIERO; VANDERLINDE, 1954).

No Brasil, em 1941 foi fundada a DF Vasconcellos, empresa brasileira de instrumentação óptica que desenvolveu equipamentos para o exército brasileiro e na área da Topografia desenvolveu teodolitos amplamente utilizados em território nacional (SOUSA; ROSAS, 2019). O desenvolvimento de alguns instrumentos pela DF Vasconcellos aconteceu em pareceria com a EPUSP, que passou a utilizar estes teodolitos em aulas e trabalhos de campo na década de 1970 (CINTRA, 1993).

Em meados do Século XX, com o início da Guerra Fria, as evoluções e transformações passaram a ocorrer em um ritmo ainda mais acelerado. Foi durante esse período que o desenvolvimento da eletrônica, das telecomunicações e da informática começa a ganhar força e assim surgiram instrumentos para diversos fins que integram essas tecnologias.

$\mathrm{Na}$ área da Topografia e ciências afins podem ser citados o desenvolvimento do Sensoriamento Remoto e do GNSS, o surgimento de modelos digitais de terreno, os níveis eletrônicos, os medidores eletrônicos de distância (MED), teodolitos eletrônicos e cadernetas eletrônicas que através de sua integração, deram origem às Estações Totais. Também surgiram recursos computacionais que permitiram realizar cálculos, processamento dos dados e desenhos assistidos por computador (WOLF, 2002; SCHERER; LERMA, 2009).

Outro ponto importante desse período foi a uniformização e padronização de sistemas e referências, por exemplo com a adoção de Greenwich como meridiano de origem (isso desde fins do XIX, com sua implantação efetiva nos inícios do XX), a recomendação de adoção projeção UTM, em meados do século XX, fatores estes que contribuíram para a cooperação internacional e início da globalização na Topografia e áreas afins.

O fim do Século XX e início do Século XXI marca uma nova era em que a informação passou a se disseminar de forma cada vez mais rápida com o desenvolvimento da internet, da computação pessoal e da telefonia móvel, criando um ambiente propício para o surgimento e desenvolvimento do mundo digital. No campo da Topografia e áreas afins, os instrumentos passaram a contar cada vez mais com tecnologia e componentes eletrônicos embarcados, permitindo a robotização, controle remoto e obtenção e manipulação de um volume de dados digitais cada vez maior. O lançamento de equipamentos com incrementação e inovações tecnológicas passou a acontecer em ritmo vertiginoso, fazendo com que a obsolescência acontecesse mais rapidamente.

\subsection{Evolução do Ensino de Topografia na Escola Politécnica da Universidade de São Paulo}

No curso de Engenharia Civil, para acompanhar a evolução das tecnologias, os regulamentos, legislações e políticas educacionais avançaram, proporcionando mudanças que se analisam na sequência.

Ao longo de sua história a EPUSP passou por 15 mudanças de regimento. Algumas pouco influenciaram no ensino de Topografia; no entanto, outras tiveram grande impacto. A mudança de regimento influenciada pela fundação da Universidade de São Paulo em 1934 proporcionou algumas mudanças estruturais na Escola (GOLDEMBERG, 2015); no entanto, no que se refere à disciplina de Topografia e ao seu ensino, foram menores. Anos antes, no final da década de 1910 e início da década de 1920, o afastamento por motivos de saúde do até então lente catedrático de Topografia o Dr. João Duarte Júnior, que fora substituído pelo Dr. Lúcio Martins Rodrigues, trouxe mudanças e evoluções de maior peso para o ensino da Topografia.

O professor Lúcio Martins Rodrigues, catedrático e depois diretor da Escola e reitor da USP, junto com seus colegas Francisco Behring e Rogério Fajardo, foram precursores no ensino da Astronomia em São Paulo. Rogério Fajardo publicou, em 1907, na "Revista Polytechnica", um estudo sobre a evolução da geodésia dividido em 6 partes. O professor Lúcio Martins Rodrigues foi responsável pelo projeto do Observatório 
Astronômico da Escola Politécnica na Praça Buenos Aires construído em 1933 (SANTOS, 2014); local e observatório que foram utilizados para aulas e trabalhos de campo de Topografia. Sobre as aulas de topografia, promoveu mudanças, inclusão de conteúdo: abordagem da teoria dos erros como um tema independente e importante para a Topografia; abordagem de novas projeções cartográficas; utilização dos teodolitos Keuffel \& Esser nas aulas e trabalhos práticos; locação topográfica; e o aprofundamento em Geodesia e Astronomia (RODRIGUES, 1923).

Também foram lentes ou assistentes de ensino de Topografia na EPUSP até a década de 1960 os professores. Henrique Jorge Guedes, Paulo Ferraz de Mesquita e Francisco Salles Vicente de Azevedo, que deram continuidade às novas contribuições para o ensino. Nesse campo, principalmente o Professor Paulo Ferraz de Mesquita contribuiu com publicações de textos no campo da astronomia em edições da Revista "Polytechnica" (MESQUITA, 1934), livro de Topografia (MESQUITA, 1969) e sua tese sobre o instrumento nível-diastímetro (MESQUITA, 1959), além de analisar e recomendar livro técnico sobre topografia para o Ministério da Educação e Cultura (MEC) (MESQUITA, 1966).

Sobre as aulas e trabalhos de campo cabe ressaltar a importância deste no aprendizado e consolidação de conceitos trabalhados na Topografia. Executar um levantamento topográfico, desde o seu planejamento até a obtenção dos produtos, passando pelas diversas etapas do trabalho, é um exercício rico e completo para a formação do Engenheiro Civil. Mesmo que estes, em sua grande maioria, não venham a trabalhar diretamente com a Topografia, executando levantamentos topográficos e outros serviços, os conhecimentos na área e um mínimo sobre o funcionamento e operação de equipamentos é importante.

Por isso, sempre se deu muita importância ao que, por muito tempo, foi chamado de exercício de férias e atualmente é chamado de projeto final, que tem como objetivo dar a oportunidade ao aluno de vivenciar esta experiência (CINTRA, 2012). A área para esse levantamento variou ao longo do tempo: Campos do Jordão, imediações do Estádio do Pacaembu, Praça Buenos Aires, Cidade Universitária de uma maneira geral, entorno do Prédio da Engenharia civil ou até mesmo de livre escolha pelos grupos.

As transformações mais profundas no ensino estavam vinculadas à mudança do docente titular da cadeira (cátedra), sistema que regia as Universidades e Faculdades brasileiras. As aulas magistrais eram dadas pelo catedrático e as práticas pelos lentes e assistentes.

Esse sistema alterou-se na década de 1960, quando ocorreram uma série de reformas no modelo do Ensino Superior Brasileiro promovidas pelo governo militar. Esse momento concretizou-se com a Reforma Universitária de 1968 (BRAGGIO, 2019), que criou condições para que o Ensino e a Pesquisa passassem a estar mais articulados dentro das instituições; as cátedras vitalícias foram abolidas introduzindo o regime departamental, foi institucionalizada a carreira docente, incluindo o ingresso e a progressão na carreira através da titulação acadêmica: assistente, mestre, doutor, adjunto e titular, vigente até nossos dias, com leves alterações (MARTINS, 2009).

Na EPUSP, a reforma foi implantada em 1971/1972, anos em que foram criados os departamentos. A Topografia, por um curto período, esteve ligada ao Departamento de Hidráulica (PHD, atualmente PHA Departamento de Engenharia Hidráulica e Ambiental), ficando, posteriormente e até nossos dias, vinculada ao Departamento de Engenharia de Transportes (PTR).

Nessa reforma foram extintas as aulas e as cadeiras, sendo criadas as disciplinas que estavam vinculadas aos departamentos. Outra grande mudança foi a concentração de esforços e otimização de recursos: as disciplinas básicas (Cálculo, Física, Direito, Português), passaram a ser dadas pelos Institutos de Matemática, Física, Faculdade de Direito e de Letras). No que diz respeito à Topografia, foram alocados à Politécnica e ao PTR os docentes dos Cursos de Arquitetura (FAU), Geologia (IG) e Engenharia de Minas (PMI - Departamento de Engenharia de Minas e Petróleo), com 4, 2 e 2 docentes, respectivamente. O regime anual, com média 7,0 de aprovação no período normal, foi substituído pelo semestral, com média 5,0.

Até a reforma, o ensino de Topografia e áreas afins ocorreu, na maior parte do tempo, em duas cadeiras e uma aula: a cadeira de Topografia e a de Geodésia e Astronomia, ambas com duração de 1 ano, e a aula de Desenho Topográfico e Cartográfico com a mesma duração. A partir da reforma foram criadas as disciplinas de Topografia I e Topografia II, cada uma com carga horária de quatro horas aula e duração de um semestre. Houve assim uma redução de carga horária, junto com a inserção de novos conteúdos devido às mudanças 
tecnológicas ocorridas.

Nessa mesma década de 1970, no âmbito da reforma, inicia-se a Pós-Graduação, pensando também na formação e carreira docente. Com isso propiciou-se o incremento das pesquisas em nível de mestrado (início em 1976 no PTR) e doutorado (início em 1983), com a produção de dissertações e teses. Com o tempo, alguns docentes finalizaram seu doutorado e novos docentes começaram a ser contratados, pelo menos com nível de mestrado; tendo diversos deles passado algum tempo em Universidades do exterior. Tudo isso teve um influxo muito benéfico, elevando o nível das aulas de graduação, e propiciando a introdução de novos conceitos, como Modelo Digital de Terreno (MDT), Computação Gráfica, desenho assistido por computador (CAD), Cartografia digital, Sistemas de Projeção UTM, renovação da Aerofotogrametria, e Geoprocessamento/ Sistemas de Informações Geográficas (SIG), para o ensino da área, em nível de graduação e pós-graduação.

A partir do final da década de 1990 com as mudanças e evoluções nas Tecnologias da Informação e Comunicação (TIC), as Instituições de Ensino Superior passaram por mudanças e estão ainda vivendo um momento de adaptações a essa nova realidade (LEITE; RIBEIRO, 2012). A informática e a eletrônica se consolidaram no ensino de Topografia, seja pelo uso de recursos audiovisuais ou de softwares específicos de Topografia nas aulas, seja na utilização dos instrumentos Topográficos com eletrônica embarcada.

No que tange às disciplinas da área, na década de 1990, estas passaram a se chamar Informações Espaciais I e II, com uma redução de carga horária de duas horas aula na segunda disciplina. Essa redução deveu-se à introdução da disciplina de Geoprocessamento. A criação desta disciplina teve a contribuição do Prof. Dr. Marcos Rodrigues ao voltar de um período de estudos na Inglaterra e publicação da tese de Livre Docência sobre Geoprocessamento (SOUSA et al., 2004).

Seguindo a evolução da área, em 2015, os componentes curriculares passaram a se chamar Geomática I e II. Com o objetivo de auxiliar o enfrentamento da diminuição de carga horária e permitir o aprofundamento do conhecimento a estudantes com interesse pela área, disciplinas optativas sobre projeções cartográficas, posicionamento por satélites e geoprocessamento foram criadas. Houve também a extinção da $2^{\text {a }}$ disciplina (2 créditos), em função da filosofia da reforma da Estrutura Curricular 3 (EC3). Essa mudança teve como objetivo sair de uma formação caracterizada por uma forte especialização com raízes em diretrizes da década de 1980 (Estrutura Curricular 2) passando a uma concepção de formação mais ampla, generalista e flexível, introduzindo o contato com a Engenharia e disciplinas da habilitação específica logo no $1^{\circ}$ semestre do curso (AMARAL, 2014; BALBO, 2017). Por essa razão, a disciplina Geomática I passou a ser trabalhada logo no $1^{\circ}$ Semestre de Engenharia Civil. A transformação da Geomática II também se deveu a uma diretriz de diminuição da carga horária das disciplinas obrigatórias.

Quanto aos equipamentos de Topografia utilizados na EPUSP entre o final do Século XX e início do Século XXI, é preciso salientar que foram adquiridos MED, nível automático, nível digital, teodolito eletrônico, trena eletrônica, estação total, receptor de navegação GPS - Sistema de Posicionamento Global, utilizados nas aulas práticas. A grande maioria desses equipamentos foi adquirida em quantidade para serem utilizados em aulas e trabalhos de campo, para todos os alunos, enquanto outros tiveram a aquisição de poucos exemplares (muitas vezes apenas um) para ser utilizado mais intensivamente em nível de pesquisa na pósgraduação e para ilustrar algumas aulas da graduação. Concretamente nível digital e receptores GNSS geodésicos foram adquiridos com o objetivo de servirem mais para a pesquisa, utilizando-se, no entanto, receptores móveis em uma ou duas aulas de campo. Posteriormente, na segunda década do Século XXI foram comprados equipamentos mais modernos e com melhor precisão, como estações totais com prumo à laser (em quantidade para ser utilizada em aula), estação total robótica e laser scanner (apenas um de cada para ser utilizado em pesquisa e para ilustração em aulas).

A compra de poucos instrumentos de certo tipo está ligada à pouca necessidade e frequência de uso do mesmo em aulas de graduação e à necessidade de um ou dois exemplares para a pesquisa em nível de pósgraduação. A única exceção é o nível digital, que só seria utilizado em uma aula prática durante todo o curso e tem pouca utilização em pesquisa ou aula de pós-graduação. Em todo caso, é feita uma demonstração na correspondente aula. Por outro lado, isso não impede uma boa formação na área e que permita o aluno estar preparado para aprender e utilizar qualquer tipo de equipamento, independente de marca, modelo e tecnologia embarcada. 


\subsection{Evolução do Ensino de Topografia Frente aos Avanços Científicos, Metodológicos e Tecnológicos: Linha do Tempo}

Neste item são apresentadas as principais evoluções na área da Topografia e na EPUSP que proporcionaram mudanças no ensino da Topografia na Escola. Esses fatores de mudança e evolução são apresentados em linhas do tempo possibilitando estabelecer conexões entre elas e verificar e analisar como o ensino da Topografia respondeu a estas transformações.

Para possibilitar a apresentação e a análise, a linha do tempo foi dividida em 5 períodos, gerando assim, 5 linhas: de 1893 à década de 1920 - fundação e anos iniciais da Escola Politécnica (Figura 1); da década de 1930 à década de 1950 - fundação da USP e anos de regime de cátedras (Figura 2); décadas de 1960 e 1970 Reforma Universitária (Figura 3); décadas de 1980 e 1990 - início da popularização da informática (Figura 4); e Século XXI - período de alta celeridade nas inovações tecnológicas e surgimento do termo Geomática (Figura $5)$.

A seguir apresenta-se e comenta-se brevemente cada uma dessas época e linhas do tempo associadas às figuras. As informações apresentadas em azul estão relacionadas com marcos históricos relacionados com a EPUSP, enquanto as informações apresentadas em preto, ocorreram em nível mundial.

A Figura 1 representa o fim do Século XIX e início do Século XX, um período de grandes evoluções científicas no campo das teorias, conceitos e experimentações que possibilitaram inovações e avanços tecnológicos no futuro. Um exemplo disso são as fotografias aéreas, que antes eram adquiridas a bordo de balões, o advento da aviação no início do Século $\mathrm{XX}$ foi importante para o desenvolvimento da aerofotogrametria (NOVO, 2010).

Figura 1 - Linha do Tempo dos Principais Marcos Históricos da Topografia e seu Ensino na EPUSP de 1893 - 1930

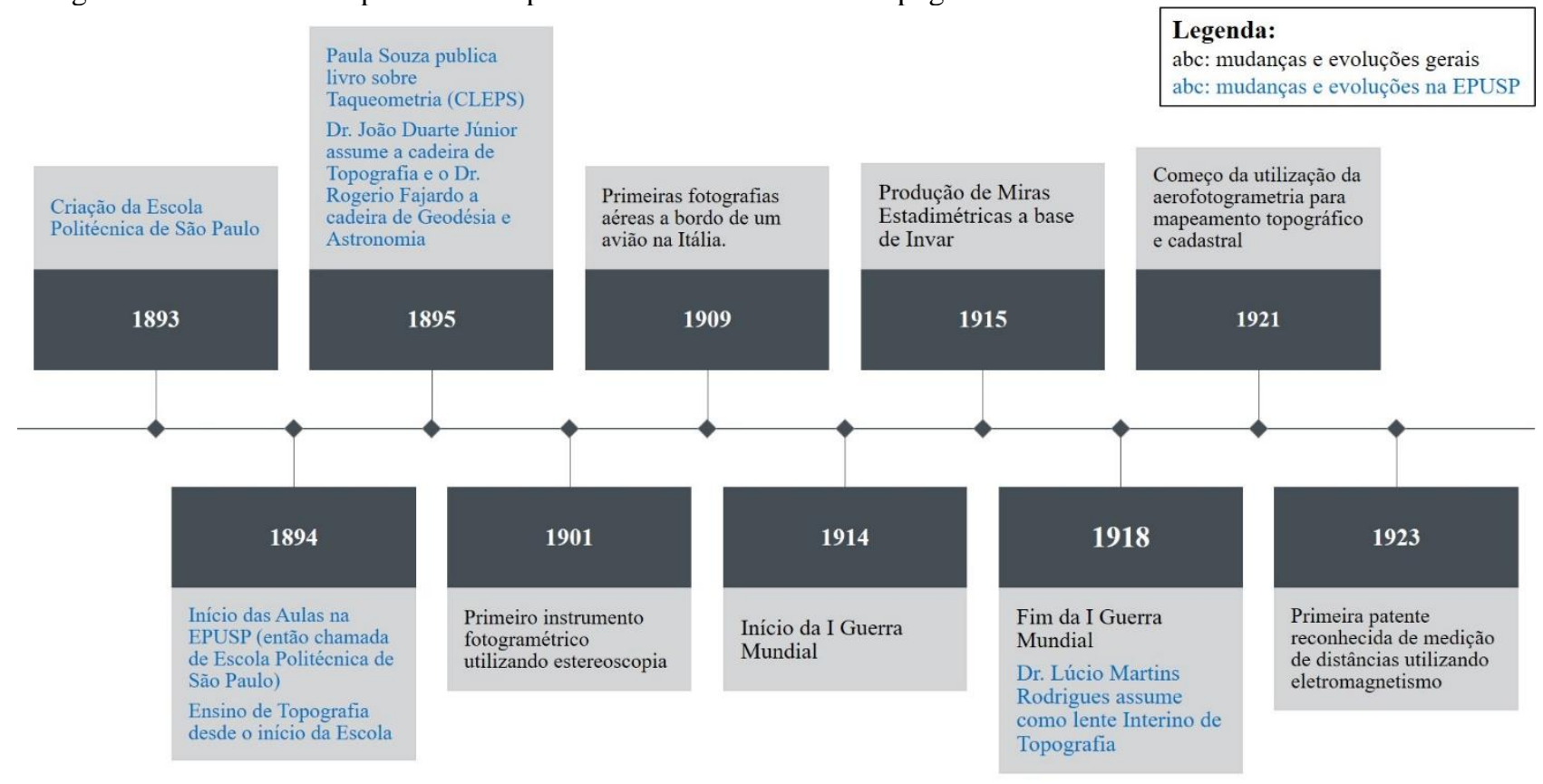

Fonte: Os Autores (2020).

A ampliação do conhecimento sobre a REM e suas possíveis aplicações, desenvolvimento também do invar - liga metálica a base de Níquel e Ferro - que viria a garantir melhor precisão em medições devido ao seu baixo coeficiente de dilatação térmica (GRUNER, 1977; WASSERMANN, 1991; WOLF, 2002). Neste período também aconteceu a I Guerra Mundial, menos tecnológica do que a segunda, mas em que ocorreram avanços no campo da ciência e da tecnologia.

Na Escola Politécnica, esse foi um período que antecedeu a fundação da USP e período em que o Prof. Dr. Lúcio M. Rodrigues entrou para o corpo docente da Escola, vindo, na década de 1920, a promover 
mudanças no ensino da Topografia e a inclusão de novos conteúdos.

Relacionado com a Figura 2 (1931-1960), no final da década de 1930 teve início a II Guerra Mundial que trouxe avanços no campo da Topografia, Geodésia, Cartografia e Aerofotogrametria. Nesse período os instrumentos passaram a ser mais precisos, mais leves e portáteis, com processos de instalação e uso mais simples, permitindo realizar levantamentos com maior rapidez. O conhecimento espacial foi um dos fatores decisivos na II Guerra Mundial, e todo o desenvolvimento científico, metodológico e tecnológico do período foi importante para o surgimento da produção analítica do conhecimento espacial, ou seja, foram criados mecanismos que permitiam a realização de processos e cálculos através desses instrumentos (CLARKE; CLOUD, 2000; HARTCUP, 2000).

Figura 2 - Linha do Tempo dos Principais Marcos Históricos da Topografia e seu Ensino na EPUSP de 1931-1960

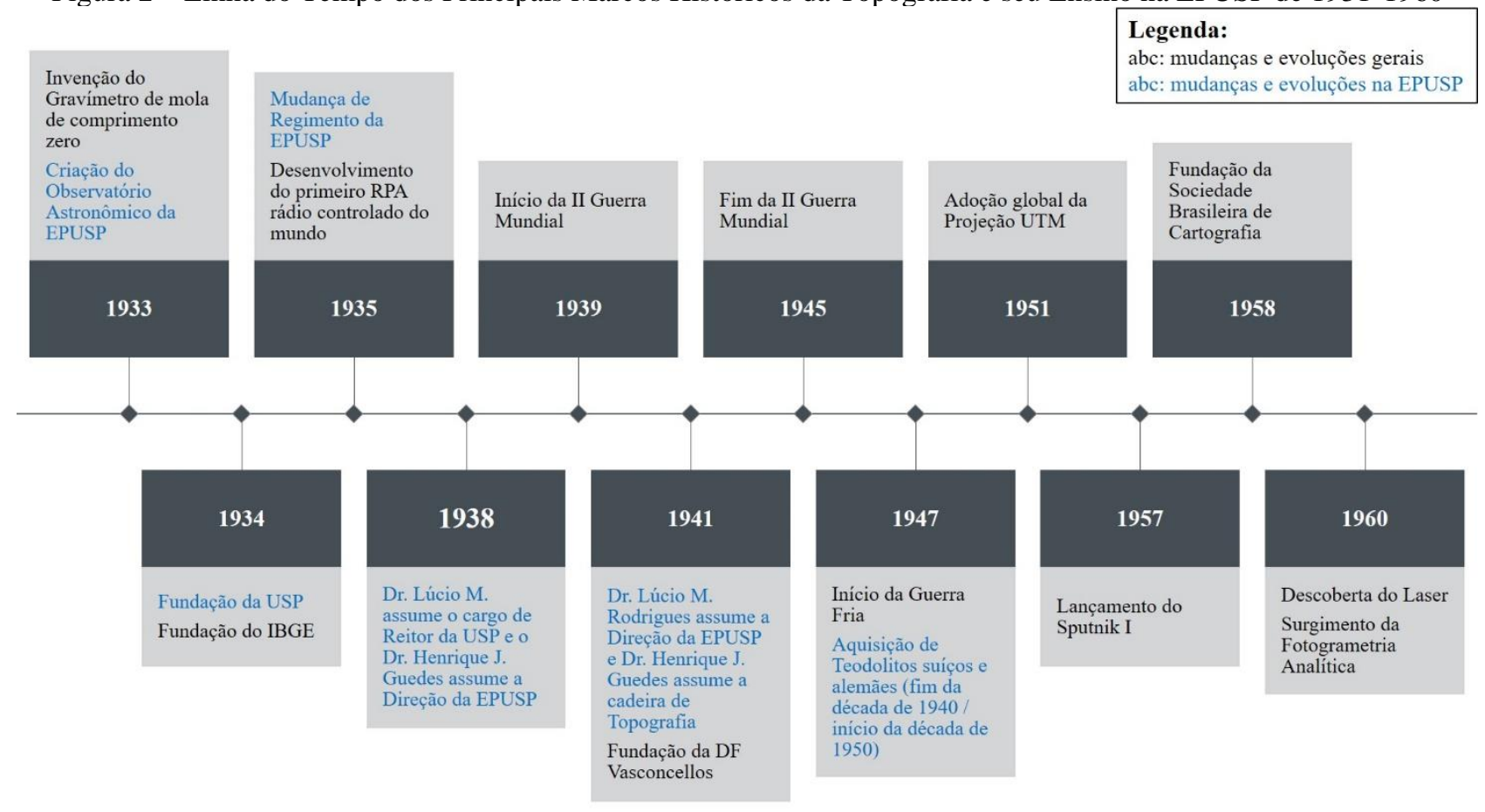

Fonte: Os Autores (2020).

Os instrumentos topográficos dessa época, principalmente teodolitos de fabricação suíça e alemã, foram adquiridos pela EPUSP na década de 1950. No entanto, foram comprados em pouca quantidade, sendo mantido o teodolito Keuffel \& Esser como equipamento mais utilizado em aulas e trabalhos de campo.

A quantidade de equipamentos para uso dos alunos supunha grupos de até 5 alunos, em turmas de até 50 alunos, gerando 10 grupos. Posteriormente as turmas foram aumentadas para 60 alunos e adquiriram-se 12 equipamentos de cada tipo.

Outro campo desenvolvido durante a II Guerra Mundial foi o das projeções cartográficas. No período pós-guerra, dada a necessidade e tendência de uniformização e padronização de informações em diversas áreas das ciências, adotou-se, em 1951, a recomendação do uso global da Projeção UTM. A primeira utilização da UTM no Brasil foi no mapeamento e produção das cartas topográficas em 1:50.000 do IBGE, a partir de 1962 (voo da Força Aérea Americana - USAF, em convênio de colaboração com o Brasil). Na EPUSP a introdução deste tema nas aulas ocorreu no final da década de 1980 (CINTRA, 1986).

O fim da década de 1940 e a década de 1950 foram marcados pelo início da Fotogrametria Analítica e o Sensoriamento Remoto, o laser, o desenvolvimento da eletrônica e da informática começa a ganhar força (MCDOUGALL, 1985).

Passando à análise da terceira linha do tempo (Figura 3), pode-se destacar que os avanços na área da Topografia e ciências afins aos poucos começam a aparecer nos registros do conteúdo das disciplinas da área na EPUSP. Devido a inviabilidade e até mesmo impossibilidade de acesso a algumas tecnologias, estes conteúdos, muitas vezes, foram tratados apenas de forma teórica, conceitual e demonstrativa. No entanto, neste momento da história, a velocidade de propagação de novas ideias, conceitos e metodologias não era a mesma 
da atualidade, sendo que no Brasil havia uma tendência de demora de chegada das informações e tecnologias. Um exemplo é o tempo que levou para a difusão e uso da projeção UTM no Brasil, bem como de seu ensino.

Nas décadas de 1960 e 1970 começaram a ser desenvolvidos e posteriormente comercializados equipamentos eletrônicos e recursos computacionais que iriam impactar substancialmente a área da Topografia e ciências afins como por exemplo os primeiros lançamentos comerciais de instrumentos como MED, teodolitos eletrônicos no início da década de 1960 e das estações totais em 1970. Há também o início do desenvolvimento do GNSS, surgimento das primeiras técnicas de varredura 3D em 1962, desenvolvimento do sensor imageador CCD (charge-coupled device) em 1969, primeiras calculadoras eletrônicas durante a década de 1960, surgimento do SIG em 1963 e primeiras experiências utilizando RPA na fotogrametria em 1980 (RÜEGER, 1990; WOLF, 2002; MONICO, 2008; SCHERER; LERMA, 2009).

Figura 3 - Linha do Tempo dos Principais Marcos Históricos da Topografia e seu Ensino na EPUSP de 1961-1980

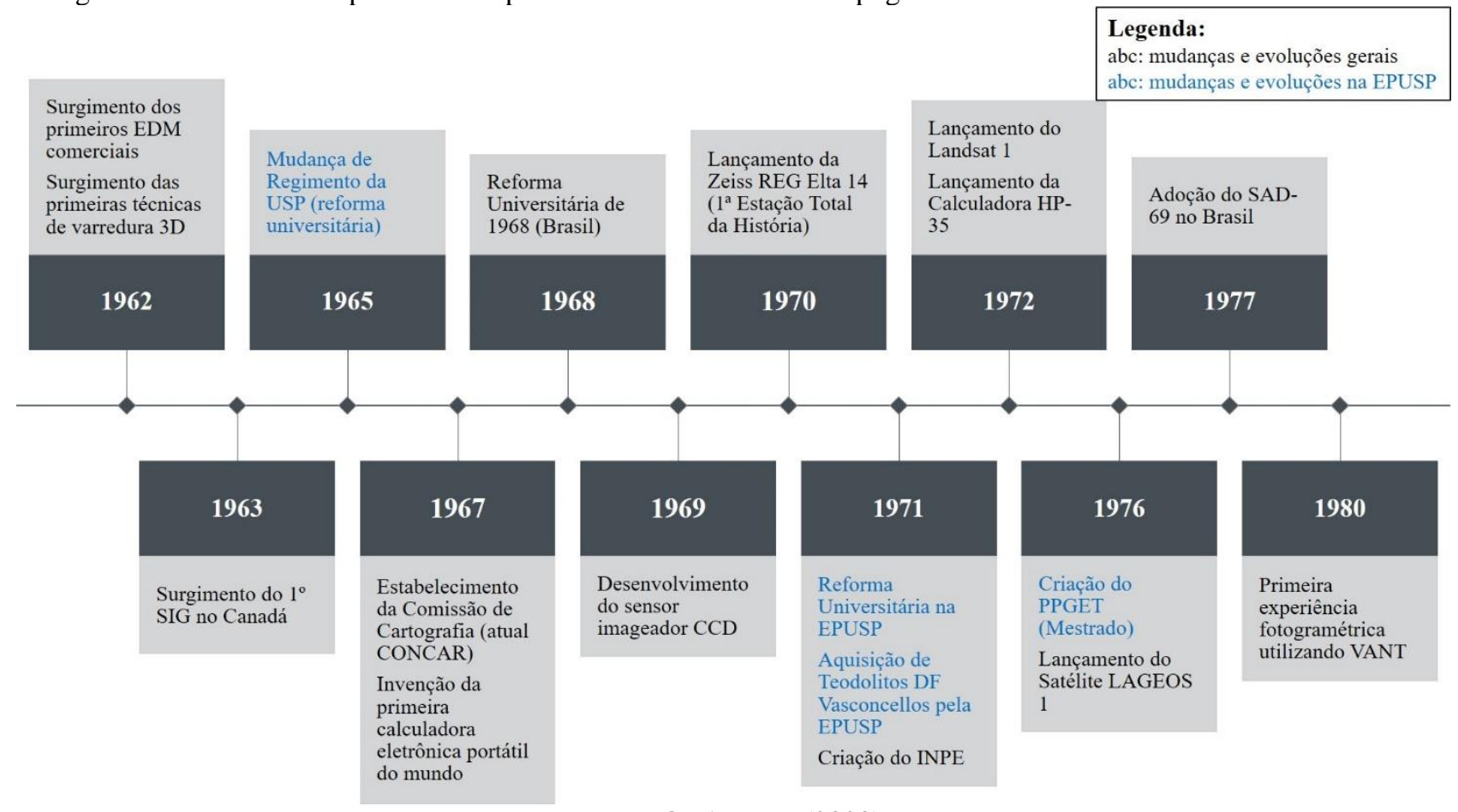

Fonte: Os Autores (2020).

No Brasil foi no período da ditadura militar que ocorreu a Reforma Universitária de 1968 que dentre outras medidas acabou com o sistema de cátedras e instituiu a carreira docente e o sistema departamental nas Universidades Brasileiras, coisa que, vista a longo prazo, foi bastante salutar. Na USP, essa alteração foi aprovada em 1965 e na EPUSP foi implementada no início da década de 1970. Essa mudança teve um impacto nas disciplinas de Topografia que passaram a ser lecionadas em 2 semestres, e não mais em 2 anos, diminuindo substancialmente a carga horária de ensino.

Em 1977 o SAD-69 foi adotado como sistema geodésico de referência oficial do Brasil. Nessa mesma década há registros nos conteúdos programáticos da disciplina da abordagem de sistemas terrestres de referência locais. Os sistemas SAD-69 e Córrego Alegre eram abordados de forma breve em uma aula, passando a ser mais desenvolvido a partir do final da década de 1980 junto com a introdução do assunto na pós-graduação.

No entanto, no que diz respeito aos instrumentos, o uso de calculadoras, por exemplo, começa a aparecer nas disciplinas de Topografia na segunda metade do Século XX. Pode-se dizer que a EPUSP facilitava para os alunos as calculadoras FACIT e outras ${ }^{1}$ calculadoras mecânicas que, a partir da década de 1970, começaram a ser substituídas por calculadoras eletrônicas. Aos poucos essa facilitação tornou-se desnecessária, pois os alunos começaram a ter suas próprias.

\footnotetext{
${ }^{1}$ Para mais informações sobre as calculadoras e outros instrumentos acessar o site do Museu Virtual do LTG em https://ltgwebmstr.wixsite.com/ltgptr/museu-virtual
} 
Instrumentos eletrônicos como a estação total e teodolitos eletrônicos começavam a ser desenvolvidos na década de 1970, estes tinham custo muito elevado e sua produção e utilização em massa veio a ocorrer décadas depois. Como dito, na década de 1970 a EPUSP adquiriu teodolitos analógicos DF Vasconcellos para uso nas aulas e trabalhos de campo. Essa aquisição ocorreu devido ao menor custo desses instrumentos, que por ser de fabricação nacional, não era acrescido da tributação de importação e também pela mais fácil manutenção do equipamento; além da fabricante desenvolver instrumentos em parceria com a USP.

Passando à análise da linha 4 do tempo (1881-2000) (Figura 4), pode-se dizer que na década de 1980 a pesquisa na área da Topografia e Geodesia começa a ganhar força na EPUSP com a autorização do funcionamento do curso de Doutorado do Programa de Pós-Graduação em Engenharia de Transportes (PPGET) em 1983. A produção na área da Topografia e ciências afins em nível de Pós-Graduação através do PPGET e do Laboratório de Topografia e Geodésia (LTG) possibilitaram o desenvolvimento de pesquisas em diversos campos e temáticas da área, que se refletiram na graduação.

Figura 4 - Linha do Tempo dos Principais Marcos Históricos da Topografia e seu Ensino na EPUSP de 1981-2000

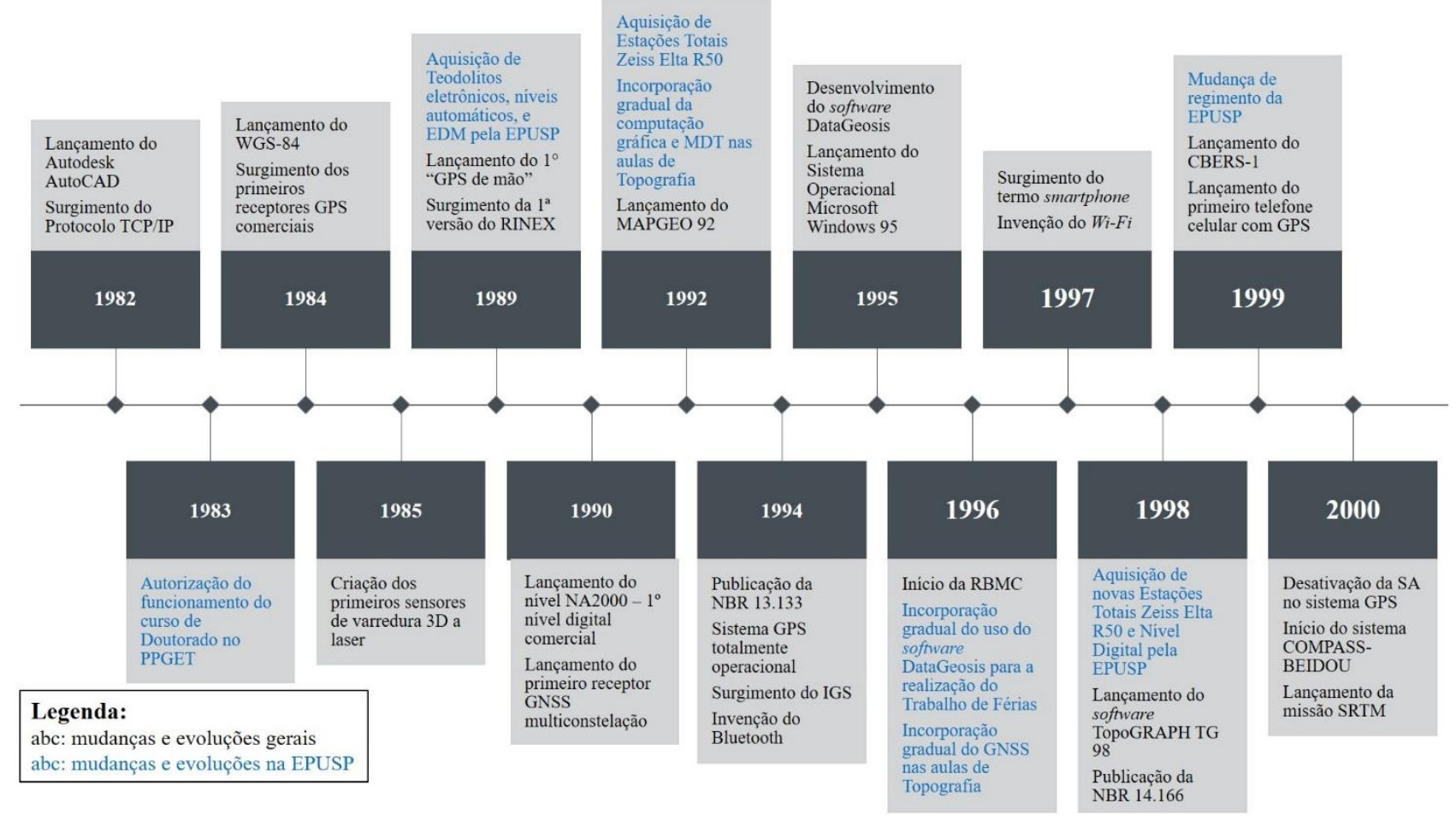

Fonte: Os Autores (2020).

Este também foi um período de grande desenvolvimento de softwares aplicados. O CAD e softwares específicos de Topografia permitiram otimizar processos, e o tempo despendido nos cálculos (trabalho de escritório e processamento dos dados). No ensino de Topografia da EPUSP inicialmente aparece o CAD a partir da década de 1990, quando este, junto com a computação pessoal e a computação gráfica se torna mais acessível auxiliando o desenho topográfico (CINTRA, 1993). No final da década de 1990, com a aquisição das estações totais pela EPUSP, foi possível iniciar a utilização de programas específicos de Topografia (DataGeosis) para a transferência e processamento dos dados dos levantamentos do Trabalho de Férias.

Diversas Normas Brasileiras para a área da Topografia e ciências correlatas, como a NBR 13.133 e NBR 14.166, foram desenvolvidas com participação de docentes do PTR/EPUSP. Inclusive, muitas das reuniões para discussão e desenvolvimento das normas ocorreram nas dependências do departamento.

A Cartografia Digital, o Geoprocessamento, Bases Cartográficas, Sistemas Geodésicos de Referência são assuntos que começaram a ser tratados no final dos anos 90 , mesmo com a diminuição de carga horária (em 1999) com a mudança de regimento da EPUSP e a reformulação das disciplinas que ganharam os nomes de Informações Espaciais I e II.

No campo dos instrumentos, nesse período foram adquiridos os primeiros instrumentos topográficos eletrônicos como MED e teodolito eletrônico. Estações totais Zeiss Elta R50 para uso em aulas e trabalhos de 
campo foram adquiridas em duas levas: a primeira no início da década de 1990 em troca por sacas de café com países da Europa Oriental e em 1998 com verba da Fundação Armando Alvares Penteado (FAAP), em função da doação de patrimônio do Conde, cujos rendimentos devem ser empregados em laboratórios de graduação, como cláusula vinculante.

A abordagem teórica e conceitual deste instrumento (Estação Total) já vinha sendo realizada anteriormente à sua aquisição, quando o professor Carlos Rodrigues Ladeira fez uma grande pesquisa sobre o assunto, com uma publicação interna no fim da década de 1970; que além de permitir a consolidação do conhecimento desenvolvido na prática do uso do instrumento, também foi aliada à necessidade imposta pela redução de carga horária, uma vez que a estação total permite a otimização do tempo despendido para o levantamento em campo.

O GPS se tornou operacional e no ano 2000 teve a disponibilidade seletiva desativada, caminhando para a popularização e consolidação do uso civil do GNSS. Na EPUSP o posicionamento por satélites inicialmente foi abordado em nível de pós-graduação no início da década de 1990 possibilitando sua abordagem em nível de graduação no final dessa década, com muita contribuição dos docentes contratados no início da década.

Com relação à linha do tempo n. 5 (2000-2020) (Figura 5), pode-se iniciar dizendo que o Século XXI é marcado pelo ritmo vertiginoso de inovações e avanços tecnológicos onde a obsolescência dos instrumentos e recursos computacionais se tornam cada vez maior e mais rápida e com alto grau de digitalização do mundo. Este cenário é repleto de desafios e possibilidades para a área da Geomática e de seu Ensino (SLADE, 2006; LI; SHEN; WANG, 2018; SILVA, 2020).

Figura 5 - Linha do Tempo dos Principais Marcos Históricos da Topografia e seu Ensino na EPUSP no Século XXI.

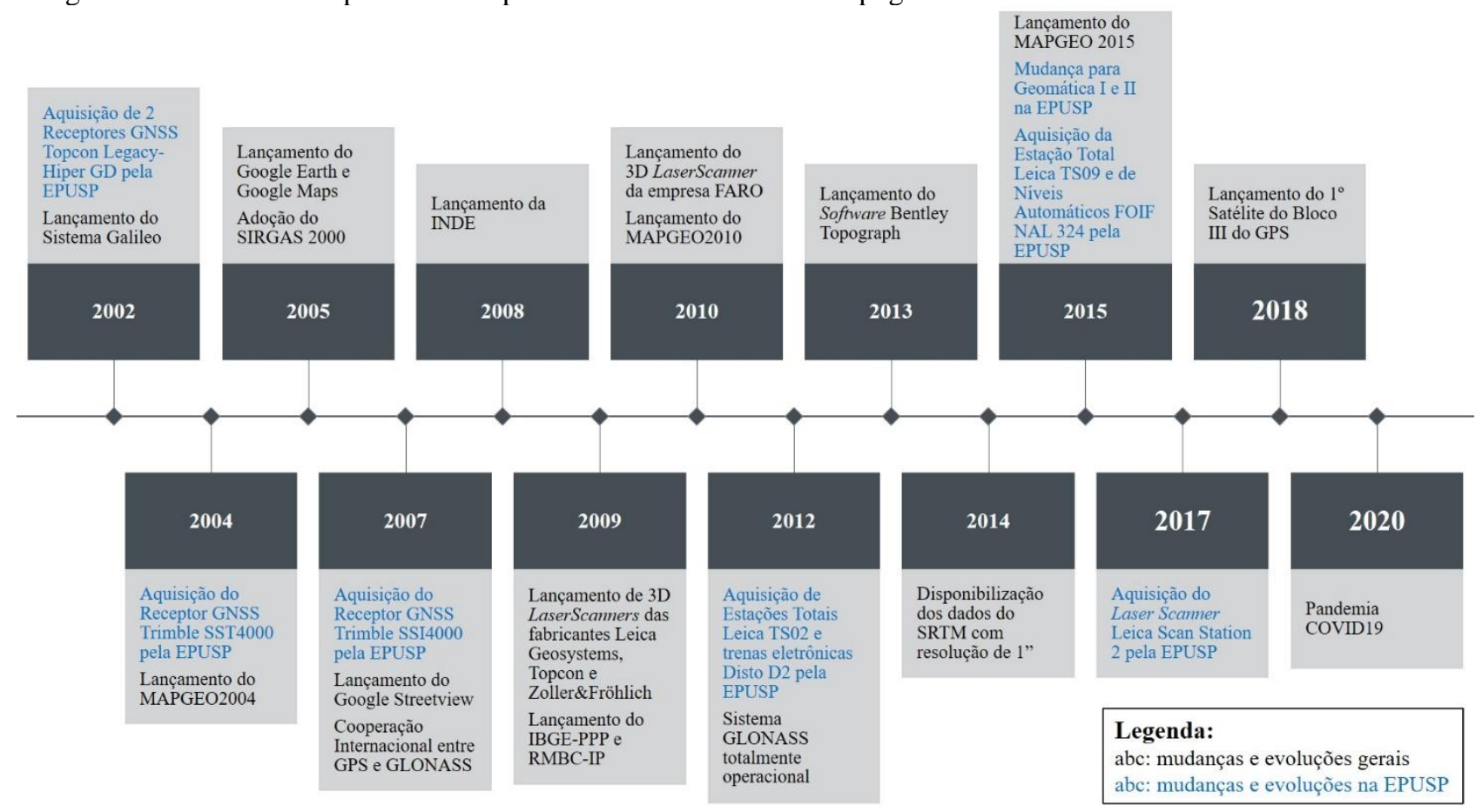

Fonte: Os Autores (2020).

Como ocorreu e ficou claro em outros períodos, também neste, no ensino da Topografia avanços metodológicos, científicos e tecnológicos foram inseridos no conteúdo das disciplinas da área, como por exemplo o uso de Estações Totais mais modernas, com prumo a laser e com melhor precisão. Disciplinas que em 2015 foram alteradas para Geomática I e II, havendo assim uma reorganização e reestruturação do ensino da área pelo LTG e, paralelamente do Laboratório de Geoprocessamento (LGP). Instrumentos com maior desenvolvimento tecnológico foram adquiridos para uso massivo em aulas e trabalhos de campo de graduação como a Estação Total Leica TS02, as trenas eletrônicas disto D2, os níveis automáticos FOIF e receptores GPS de navegação. Outros equipamentos foram adquiridos mais para utilização em nível de pós-graduação como a 
estação total Leica TS09, receptores GNSS geodésicos e do Laser Scanner Leica Scan Station 2.

No final do ano de 2019, em 11 de novembro, foi assinado um convênio entre a EPUSP e a Trimble Europe B. V. que se presta a doação de uso de instrumentos desta fabricante (DOSP, 2019). Esse acordo permitirá a atualização e uso de diversos instrumentos da área da Geomática em nível de graduação e pósgraduação.

\section{CONTRIBUIÇÕES DA PÓS-GRADUAÇÃO PARA O ENSINO DA TOPOGRAFIA}

A Pós-Graduação em Engenharia de Transportes foi oficialmente reconhecida em nível de mestrado em 1976 e em nível de doutorado em 1983 (LOSCHIAVO DOS SANTOS, 1985). Na década de 1980 não existia oficialmente uma linha de pesquisa em Topografia ou áreas afins, no entanto, primeiramente através de orientações do Prof. Felippe Augusto Aranha Domingues, iniciaram-se as pesquisas.

A criação da linha de pesquisa oficialmente com esse título em informações espaciais ocorre no final dos anos 1990. Este trabalho focalizará a atual linha de Cartografia, Geodésia e Topografia. Para este trabalho foram consultados os Currículo Lattes de seis docentes que têm ou tiveram vínculo com o LTG e o PPGET: Jorge Pimentel Cintra (início em 1986); Nicola Paciléo Netto (1991 até 2009); Denizar Blitzkow (início em 1990); Edvaldo Simões da Fonseca Junior (início em 2004); Ana Paula Camargo Larocca (2009 até 2013); e Flavio Guilherme Vaz de Almeida Filho (início em 2014).

No âmbito do LTG, ao olhar para o currículo lattes dos seis docentes que integraram e integram o LTG, de 1990 até 2020, há um extenso volume de produção que contribuiu direta e indiretamente para o ensino da Geomática. Esse extenso volume compreende projetos de pesquisa, publicações em periódicos e anais de eventos científicos, capítulos de livros, produções técnicas, elaboração de normas e de material didático, bem como as orientações de mestrado, doutorado e iniciação científica (IC).

São consideradas contribuições diretas as pesquisas e publicações que têm como temática central o ensino, seja no desenvolvimento de alguma ferramenta, na discussão de metodologias, ou em qualquer outro tipo de abordagem que discorra sobre o ensino da área. Quanto às contribuições indiretas, são consideradas as publicações e pesquisas que constituem uma métrica e sintoma de contribuição para o desenvolvimento e evolução do conhecimento científico e inovações tecnológicas que apresentam potencial de aplicação e contribuição para o desenvolvimento do ensino em nível de graduação e pós-graduação.

Quando se lança o olhar para as temáticas em que pesquisas e publicações foram realizadas ao longo do tempo (Tabela 1) é possível compreender como o LTG em nível de pós-graduação desenvolveu pesquisas e publicações que estiveram e continuam alinhadas com o desenvolvimento e evolução científica, metodológica e tecnológica.

Dois exemplos disso são as pesquisas realizadas nas temáticas do GNSS, redes geodésicas e sistemas geodésicos de referência que contribuíram para o desenvolvimento e adoção do SIRGAS-2000 como sistema geodésico de referência oficial do Sistema Geodésico Brasileiro (SGB) e as pesquisas na área da Geodésia Física e modelos geoidais que contribuíram para o desenvolvimento do modelo geoidal brasileiro (MAPGEO) vinculado ao SGB. Estes temas, bem como a adoção do SIRGAS e os problemas da altitude na Geodésia são temas desenvolvidos no âmbito da Pós-Graduação e rapidamente incorporado e trabalhado no âmbito da graduação.

Olhando para o desenvolvimento e incidência dos temas de pesquisas e produções ao longo do tempo, pode-se verificar como estes acompanham as evoluções científicas, metodológicas e tecnológicas, possibilitando compreender como o ambiente da pós-graduação stricto sensu, onde se desenvolvem pesquisas científicas rigorosas e alinhadas com a conjuntura e as necessidades em nível regional, nacional e global, possibilita que a Instituição de Ensino Superior (IES) e seu ensino estejam acompanhando a evolução.

A Pós-Graduação além de espaço de formação de pesquisadores e realização de pesquisas é também um espaço de formação docente para atuação no Ensino Superior. A Lei de Diretrizes e Bases (LDB) da Educação Brasileira apresenta em seu artigo 66 que "a preparação para o exercício do magistério superior farse-á em nível de Pós-Graduação, prioritariamente em programas de mestrado e doutorado" (BRASIL, 1996).

Através do currículo lattes dos orientadores do PPGET vinculados ao LTG buscou-se a informação sobre as orientações de mestrado e doutorado concluídas. Com acesso aos currículos lattes dos mestres e 
doutores formados no PPGET com orientação de docentes do LTG buscou-se verificar quantitativamente informações como número de ex-alunos que tiveram alguma experiência docente, bem como verificar em que nível de ensino e tipo de IES estes exerceram ou exercem à docência (Tabela 2).

Tabela 1 - Produção científica por temas ao longo do tempo (intervalos de 5 anos) com base nos Currículos Lattes dos

\begin{tabular}{|c|c|c|c|c|c|c|c|c|c|}
\hline Temas & $\begin{array}{c}2020- \\
2016\end{array}$ & $\begin{array}{l}2015- \\
2011 \\
\end{array}$ & $\begin{array}{l}2010- \\
2006\end{array}$ & $\begin{array}{l}2005- \\
2001\end{array}$ & $\begin{array}{l}2000- \\
1996\end{array}$ & $\begin{array}{l}1995- \\
1991\end{array}$ & $\begin{array}{l}1990- \\
1986\end{array}$ & $\begin{array}{l}1985- \\
1981\end{array}$ & Somatório \\
\hline Ensino & 2 & 12 & 12 & 7 & 14 & 5 & 13 & 0 & 65 \\
\hline $\begin{array}{c}\text { Instrumentos de medição de } \\
\text { ângulos / distância / } \\
\text { nivelamento } \\
\end{array}$ & 0 & 7 & 2 & 1 & 8 & 16 & 0 & 0 & 34 \\
\hline $\begin{array}{l}\text { Posicionamento por Satélites } \\
\text { (GNSS) }\end{array}$ & 8 & 23 & 19 & 21 & 38 & 25 & 0 & 0 & 134 \\
\hline $\begin{array}{c}\text { Sistema Geodésico de } \\
\text { Referência }\end{array}$ & 3 & 5 & 3 & 21 & 15 & 9 & 2 & 0 & 58 \\
\hline Redes Geodésicas & 0 & 1 & 0 & 15 & 13 & 8 & 2 & 0 & 39 \\
\hline MDT & 1 & 0 & 5 & 8 & 8 & 7 & 3 & 2 & 34 \\
\hline $\begin{array}{l}\text { Métodos e Técnicas de } \\
\text { Levantamento }\end{array}$ & 3 & 8 & 5 & 7 & 13 & 6 & 0 & 0 & 42 \\
\hline $\begin{array}{c}\text { Base de Aferição/Calibração } \\
\text { de Instrumentos }\end{array}$ & 1 & 2 & 3 & 5 & 9 & 10 & 0 & 0 & 30 \\
\hline $\begin{array}{c}\text { Aplicações da Geomática na } \\
\text { Engenharia }\end{array}$ & 12 & 22 & 16 & 18 & 18 & 8 & 1 & 0 & 95 \\
\hline Sensoriamento Remoto & 2 & 9 & 6 & 9 & 13 & 4 & 0 & 0 & 43 \\
\hline
\end{tabular}

\begin{tabular}{|c|c|c|c|c|c|c|c|c|c|}
\hline Sensoriamento Remoto & 2 & 9 & 6 & 9 & 13 & 4 & 0 & 0 & 43 \\
\hline $\begin{array}{l}\text { Informática e Topografia } \\
\text { (CAD / Processamento de } \\
\text { Dados) }\end{array}$ & 0 & 13 & 8 & 9 & 17 & 6 & 8 & 0 & 61 \\
\hline Geodésia Física & 11 & 18 & 14 & 24 & 12 & 7 & 6 & 0 & 92 \\
\hline SIG e Geoprocessamento & 0 & 4 & 0 & 5 & 11 & 3 & 0 & 0 & 23 \\
\hline Aerofotogrametria & 2 & 1 & 1 & 5 & 3 & 2 & 0 & 0 & 14 \\
\hline VANTs & 3 & 0 & 0 & 0 & 0 & 0 & 0 & 0 & 3 \\
\hline Laser Scanner & 9 & 2 & 3 & 0 & 1 & 0 & 0 & 0 & 15 \\
\hline $\begin{array}{l}\text { Avaliação de Instrumentos / } \\
\text { Metodologias }\end{array}$ & 7 & 9 & 5 & 17 & 17 & 7 & 2 & 0 & 64 \\
\hline $\begin{array}{c}\text { Desenvolvimento de } \\
\text { Ferramenta Computacional }\end{array}$ & 2 & 4 & 7 & 7 & 8 & 0 & 2 & 1 & 31 \\
\hline $\begin{array}{c}\text { Cartografia Digital / Bases } \\
\text { Cartográficas }\end{array}$ & 4 & 4 & 4 & 20 & 21 & 11 & 0 & 0 & 64 \\
\hline
\end{tabular}

Controle de Qualidade /

Precisão de Cartas / Dados e

\begin{tabular}{cccccccccc} 
Levantamentos & 4 & 8 & 4 & 14 & 3 & 4 & 0 & 0 & 37 \\
\hline Revisão da literatura & 3 & 6 & 1 & 8 & 3 & 2 & 0 & 0 & 23 \\
\hline $\begin{array}{c}\text { Normas (Desenvolvimento / } \\
\text { Análise) }\end{array}$ & 0 & 0 & 0 & 6 & 1 & 1 & 0 & 0 & 8 \\
\hline
\end{tabular}
Fonte: Os autores (2020).

Foram pesquisados 88 formados em nível de mestrados e doutorado, sendo que destes, 56 apresentam algum registro de experiência com a docência no currículo Lattes, correspondendo a aproximadamente $64 \%$ dos pesquisados. Dentre os outros 32, quinze não tiveram registro encontrado na plataforma Lattes e dezessete não apresentam nenhum registro de experiência na carreira docente em seus lattes. De fato, muitos pósgraduados trabalhavam e trabalham na iniciativa privada, em órgãos públicos, prefeituras e outros, atuando na área de informações espaciais. Cabe ressaltar que o somatório dos totais da Tabela 2 não equivale ao número total de docentes com formação no LTG no PPGET, pois um professor pode estar em mais de uma linha da tabela, não sendo possível que um professor esteja em mais de uma coluna.

Dentre àqueles que apresentam ao menos alguma experiência na carreira docente, muitos seguiram em IES de relevância no Ensino Superior Brasileiro e se desenvolveram como pesquisadores e docentes nessas instituições, sendo que para a maior parte o início da construção de sua profissionalidade docente se deu no espaço da pós-graduação, sendo este um espaço importante para o desenvolvimento inicial da docência no Ensino Superior. Dentre os professores formados no Mestrado e Doutorado, encontram-se docentes do IME, UFPR, UNICAMP, UFMG, UNESP, USP São Carlos, UERJ, UFRJ UFU, UFV, UFSM, UEM, UNB, UFGO, UFBA, FEI, entre outras. 
Tabela 2 - Mestres e Doutores formados no LTG - PPGET com experiência em docência, com base nos Currículos

\begin{tabular}{ccccc}
\multicolumn{5}{c}{ Lattes dos docentes do PPGET - LTG. } \\
\hline Experiência & $\begin{array}{c}\text { Mestrado no PPGET } \\
\text { (apenas) }\end{array}$ & $\begin{array}{c}\text { Doutorado no } \\
\text { PPGET (apenas) }\end{array}$ & $\begin{array}{c}\text { Mestrado e Doutorado no } \\
\text { PPGET }\end{array}$ & Total \\
\hline Lecionou IES Particular & 10 & 2 & 10 & 22 \\
Leciona IES Particular & 3 & 2 & 3 & 8 \\
Lecionou IES Pública & 0 & 3 & 3 & 6 \\
Leciona IES Pública & 9 & 15 & 10 & 34 \\
$\begin{array}{c}\text { Lecionou em Escola } \\
\text { Técnica }\end{array}$ & 3 & 1 & 1 & 5 \\
Leciona em Escola & 2 & 0 & 0 & 2 \\
Técnica & & & & \\
\hline
\end{tabular}

Fonte: Os autores (2020).

\section{PERSPECTIVAS E DESAFIOS PARA O ENSINO DE GEOMÁTICA}

Os próximos anos e décadas do Século XXI apontam para uma continuidade no processo de evoluções e inovações tecnológicas em ritmos acelerados, o mesmo para a sociedade, com mudanças nos processos de interação, que cada vez mais são mediadas por tecnologias. A Educação, incluindo a área de Informações Espaciais, se vê dentro desse processo, impactada pelas evoluções na área da tecnologia e pelas mudanças comportamentais e sociais.

O Século XXI é também marcado pela interdisciplinaridade e multitarefa. Exige-se cada vez mais essas qualidades dos profissionais, além de características empreendedoras e inovadoras. Dentre essas características, não se pode perder de vista a formação teórico-conceitual dos engenheiros frente a um mundo cada vez mais voltado para a prática e em ritmo cada vez mais acelerado nas inovações tecnológicas. Portanto, uma discussão constante sobre a estrutura do ensino da Geomática, pelos docentes e pesquisadores da área tende a ser benéfica para avançar na qualidade da formação de novos engenheiros (SILVA, 2016; SILVA, 2020).

A previsão é de conhecimentos crescentes e de um tempo de ensino (número de aulas) constante, o que obriga a uma escolha de conteúdos, para evitar a superficialidade. E, escolhido o assunto, penetrar com certa profundidade para transmitir modos de pensar e raciocinar nessa área, com exemplos e casos concretos da engenharia; poucos, mas que ensinem a pensar. Deve-se garantir a transmissão / aprendizados e conceitos essenciais, possivelmente ligados à geometrização do espaço (ângulos, distâncias, coordenadas, referenciais); erros e precisão associados a medições, controle de qualidade, expressões gráficas (plantas, cartas) e sua leitura. E escolhendo, em cada época como ilustração, alguns equipamentos e seus princípios. Por exemplo, GNSS, levantamentos fotogramétricos com drone. Também se pode ampliar a formação através de módulos e cadeiras optativas dentro do Curso de engenharia civil. Pode-se também pensar que, na prática profissional, o engenheiro civil contará, necessariamente com a colaboração de especialistas de Topografia e Geodésia.

Pedagogicamente, é necessário discutir também como as TIC e as chamadas EdTechs (tecnologias educacionais) podem ser ferramentas aliadas no ensino de Topografia e Geomática. Deve-se pensar sobre a inserção, adaptação e uso de smartphones, plataformas de vídeos, de videoconferências e ensino a distância, animações e simuladores computacionais, a "gamificação" da Educação e dispositivos de realidade virtual e realidade aumentada, entre outros avanços e ferramentas tecnológicas para potencializar o ensino e a aprendizagem (KONECNY, 2002; BEDNARCZYK, 2017). As EdTechs podem ser utilizadas, por exemplo, na hipótese de diminuição das aulas de campo, possibilitando a visualização por parte do estudante do uso deste equipamento auxiliando-o a consolidar e significar os conceitos desenvolvidos em aula teórica. Isso de fato já ocorre há certo tempo, sendo utilizados em sala de aula vídeos demonstrativos de utilização e aplicação prática de alguns equipamentos, como o laser scanner, que atualmente é um assunto trabalhado desta forma.

Há também as Metodologias Ativas de Aprendizagem, que assim como as tecnologias educacionais também podem ser uma ferramenta potencializadora do processo ensino-aprendizagem e da significação e visualização prática dos conceitos trabalhados (ELMÔR FILHO et al., 2019). Tanto as Metodologias Ativas como as EdTechs também podem ser aliadas no enfrentamento da diminuição de carga horária disponível para o ensino da Geomática em cursos de Engenharia. 
Diante da Pandemia COVID-19 e da necessidade de distanciamento e isolamento social por ela imposta, muitas IES, dentre elas a EPUSP, passou a realizar o ensino mediado por tecnologias, realizado de forma remota síncrona e/ou assíncrona, ficando conhecido com Ensino Remoto Emergencial (ERE). As soluções nas IES foram diversas, e em muitos casos escolhidas e aprimoradas com o semestre letivo em curso. O ERE apressou a utilização de uma possibilidade que estava latente nas IES brasileiras e no mundo, que é a mediação tecnológica do ensino remoto e o uso de suas ferramentas no ensino presencial.

O uso emergencial da mediação tecnológica do ensino distanciado vem mostrando as potencialidades e fragilidades do uso dessas ferramentas, evidenciando que a efetividade e sucesso do ensino remoto depende de muito planejamento e vem trazendo muitas dúvidas, questionamentos, perspectivas e desafios, que deverão ser repensados e discutidos para a área do Ensino de Geomática: como desenvolver o ensino remoto de Geomática de forma efetiva? Como medir o aprendizado efetivo? Quais os modelos, técnicas e ferramentas de ensino remoto representam efetivamente uma melhoria no ensino de Geomática? Os docentes da área estão preparados para o uso dessas metodologias e tecnologias? Seria possível um curso ou uma disciplina de Geomática totalmente remoto? Um modelo híbrido (parte presencial, parte remoto) de ensino seria o mais adequado para a área? Como as aulas práticas e de levantamentos topográficos e geodésicos em campo poderão ser realizadas? Estas, entre outras questões estão postas para serem pensadas e discutidas pelos docentes e pesquisadores da área da Geomática.

\section{CONSIDERAÇÕES FINAIS}

O Ensino da Topografia e ciências afins (atualmente Geomática) na EPUSP passou por diversas fases e momentos, sendo impactado por mudanças e evoluções de diversas naturezas. As mudanças e evoluções foram absorvidas de diversas formas, inicialmente dependendo mais da ação pessoal dos lentes catedráticos, posteriormente do movimento e unidade dos departamentos e dos programas de pós-graduação.

A história de mais de um século de ensino de Topografia na EPUSP mostra que o ensino deve estar atento às evoluções e inovações científicas, metodológicas e tecnológicas que se consolidam no exercício profissional da área. As evoluções científicas e metodológicas, sempre que possível, foram rapidamente absorvidas e incorporadas no ensino da Topografia na EPUSP, quando esta não estava envolvida de alguma forma nos processos evolutivos da área.

Quanto às evoluções instrumentais, a tendência é que os instrumentos com novidades tecnológicas sejam de alto custo e pouca viabilidade econômica para serem adquiridos em larga escala, impossibilitando seu uso na graduação; no entanto, a experiência da EPUSP mostrou que isso é possível e que, nos casos extremos, apontam para formas alternativas de serem trabalhados conceitualmente e sejam mostrados resultados de pesquisa durante as aulas de graduação. Ou seja, a inviabilidade de acesso a recursos e instrumentos modernos e com alta tecnologia embarcada não é e nem pode ser um impeditivo para o desenvolvimento de uma boa formação em Geomática.

Por tudo o que ficou apontado, a formação deve estar fortemente amparada e baseada nos conceitos da Geomática, que possibilitarão que o estudante desenvolva as habilidades e competências para o exercício profissional independentemente do nível de tecnologia a que se tenha acesso, estando assim preparado para se adaptar às evoluções científicas, metodológicas e tecnológicas.

Por fim, os avanços científicos, metodológicos e tecnológicos devem ser vistos e trabalhados de forma a serem integrados no conteúdo programático das disciplinas da área, sempre tendo em conta a necessidade de privilegiar os conceitos e compreender que a tecnologia é uma ferramenta (um meio) e não deve ser vista como um fim.

\section{Contribuição dos Autores}

O autor 1 (Jhonnes Alberto Vaz) realizou: conceptualização, curadoria dos dados, investigação, visualização e redação - minuta inicial. O autor 2 (Jorge Pimentel Cintra) realizou: estrutura do trabalho, sugestão e seleção de períodos e fatos históricos, revisão final do texto. O autor 3 (Flávio Guilherme Vaz de Almeida Filho) realizou: apoio na elaboração da estrutura do trabalho, contribuição na construção do cenário 
atual e futuro, versão e revisão final do texto.

\section{Conflitos de Interesse}

Os autores declaram que não há conflito de interesse.

\section{Referências}

AMARAL, André Henrique Freitas do. PET Entrevista Fábio Cozman. Revista Autômato. Edição Especial A EC3, p. 6-8, 2014. Disponível em: <https://sites.usp.br/petmecatronica/wpcontent/uploads/sites/690/2018/04/Automato_10-compressed.pdf> Acesso em: 24 jul. 2020.

BALBO, José Tadeu. A Nova Estrutura Curricular para o Ensino de Engenharia Civil na Poli-USP. Revista Concreto \& Construções. v. 44, n. 85, p. 65-69, 2017.

BEDNARCZYK, Michal. The Use of Augmented Reality in Geomatics. In: ENVIRONMENTAL ENGINEERING $10^{\text {th }}$ INTERNATIONAL CONFERENCE, 2017, Lituânia: $27-28$ abr. Proceedings... Vilnius Gediminas Technical University, Lituânia, 2017. DOI.: 10.3846/enviro.2017.162

BRAGGIO, Ana Karine. A Gênese da Reforma Universitária Brasileira. Revista Brasileira de História da Educação. v. 19, p. 1-26, 2019. DOI.: 10402.51920.19073

BRASIL. Lei $\mathbf{n}^{\circ}$ 9.394, de 20 de dezembro de 1996. Que estabelece as diretrizes e bases da educação nacional. Disponível em: <http://bd.camara.gov.br/bd/bitstream/handle/bdcamara/2762/ldb_8.ed.pdf?sequence=1>. Acesso em: 30 maio 2020.

CAMPOS, Cristina. Ferrovias e saneamento em São Paulo. O Engenheiro Antonio Francisco de Paula Souza e a construção de rede de infra-estrutura territorial e urbana paulista, 1870-1893. 2007. 411 p. Tese (Doutorado - Área de Concentração: História e Fundamentos da Arquitetura e Urbanismo) Faculdade de Arquitetura e Urbanismo, Universidade de São Paulo, São Paulo, 2007.

CAMPOS, Cristina; GITAHY, Maria Lucia Caira. O percurso de um engenheiro politécnico paulista. Antonio Francisco de Paula Souza e a configuração das redes de infra-estrutura em São Paulo, nas últimas décadas do Século XIX. Pós. v. 16, n. 26, p. 184-200, 2009. DOI.: 10116.06231.72762.02618.4200

CINTRA, Jorge Pimentel. O ensino da Topografia nas Escolas de Engenharia. Revista de Ensino de Engenharia. v. 5, n. 1, p. 91-101, 1986.

CINTRA, Jorge Pimentel. Automação da Topografia: Do Campo ao Projeto. 1993. Tese (Livre Docência) - Escola Politécnica, Universidade de São Paulo, São Paulo, 1993.

CINTRA, Jorge Pimentel. PTR 2201 - Informações Espaciais I: Notas de Aula. São Paulo: EPUSP, 2012.

CLARKE, K. C.; CLOUD, J. G. On the origins of Analytical Cartography. Cartography and Geographic Information Science. v. 27, n. 3, p. 195-204, 2000. DOI.: 10155.91523.04000.78354.7821

DOSP, Diário Oficial do Estado de São Paulo. Diário Oficial do Estado de São Paulo de 11 de dezembro de 2019, Executivo Caderno 1. São Paulo: Imprensa Oficial, p. 78, 2019.

ELMÔR FILHO, Gabriel et al. Uma Nova Sala de Aula é Possível: aprendizagem ativa na Educação em Engenharia. Rio de Janeiro: LTC, 2019

GOLDEMBERG, José. USP 80 anos. São Paulo: EDUSP, 2015.

GRUNER, Heinz. Photogrammetry: 1776 - 1976. Photogrammetric Engineering and Remote Sensing. v. 43, n.5, p. 569-574, 1977.

HARTCUP, Guy. The Effect of Science on the Second World War. London: Macmillan Press LTD, 2000.

IHDE, Johannes; REINHOLD, Andreas. Friedrich Robert Helmert, founder of modern geodesy, on the occasion of the centenary of his death. History of Geo and Space Sciences. v. 8, p. 79-95, 2017. DOI.: 10.5194/hgss-8-79-2017 
KONECNY, Gottfried. Recent Global Changes in Geomatics Education. In: ISPRS COMMISSION VI SYMPOSIUM 2002: NEW APPROACHES FOR EDUCATION AND COMMUNICATION, XXXIV, São José dos Campos, SP, 2002. ISPRS Archives. São José dos Campos, SP: INPE, 16-18 set. 2002. Disponível em: <https://www.isprs.org/proceedings/XXXIV/part6/papers/019.pdf〉. Acesso em: 10 jun. 2020.

LEITE, Werlayne Stuart Soares; RIBEIRO, Carlos Augusto do Nascimento. A Inclusão das TICs na Educação Brasileira: Problemas e Desafios. Magis, Revista Internacional de Investigación em Educación. v. 5, n. 10, p. 173-187. Bogotá: Pontifícia Universidade Javariana, 2012. DOI.: 10.11144/Javeriana.m5-10.idtn

LI, Deren; SHEN, Xin; WANG, Le. Connected Geomatics in the big data era. International Journal of Digital Earth. v. 11, n. 2, p. 139-153, 2018. DOI: https://doi.org/10.1080/17538947.2017.1311953

LOSCHIAVO DOS SANTOS, Maria Cecília. Escola Politécnica da Universidade de São Paulo: 1894 1984. São Paulo: EDUSP, 1985.

MANIERO, Léo; VANDERLINDE, Walpy. Curso de Topografia. ed. 3. São Paulo: EPUSP, 1954.

MARTINS, Carlos Benedito. A Reforma Universitária de 1968 e a Abertura para o Ensino Superior Privado no Brasil. Educação \& Sociedade. v. 30, n. 106, p. 15-35. Centro de Estudos Educação e Sociedade: Campinas, 2009. DOI.: 10159.0S010.17330.20090.00100.002

MCDOUGALL, W. A. Sputnik, the Space Race, and the Cold War. Bulletin of the Atomic Scientists. v. 41, n. 5, p. 20-25, 1985. DOI.: 10108.00096.34021.98511.45596.2

MESQUITA, Paulo Ferraz de. Astronomia Espherica. Revista Polytechnica. 1934.

MESQUITA, Paulo Ferraz de. Análise de niveldiastímetro. 1959.Universidade de São Paulo, São Paulo, 1959.

MESQUITA, Paulo Ferraz de. Carta de Paulo Ferraz de Mesquita aos membros da Comissão do livro técnico e didático do MEC acerca da oportunidade da publicação do "Tratado teórico e prático de topografia", de Albano da França Rocha. São Paulo: 2 dez. 1966. Disponível em: <https://www.docvirt.com/docreader.net/docreader.aspx?bib=AT_Corresp\&pasta=AT\%20c\%201966.12 $.02 \&$ pagfis $=12853>$ Acesso em: 26 jul. 2020.

MESQUITA, Paulo Ferraz de. Curso Básico de Topografia, Astronomia de Posição e Geodésia. ed. 2. São Paulo: Dlp. 1969.

MONICO, João Francisco Galera. Posicionamento pelo GNSS: Descrição, Fundamentos e Aplicações. ed. 2. São Paulo: Editora Unesp, 2008.

NOVO, Evlyn M. L. de Moraes. Sensoriamento Remoto: princípios e aplicações. ed. 4. São Paulo: Blucher, 2010.

PADILHA, Rodrigo Bastos. Antônio Francisco de Paula Souza: criador da Escola Politécnica de São Paulo, engenheiro, político e educador. São Paulo: Leopardo Editora, 2010.

RODRIGUES, Lúcio Martins. Notas de Aula do Curso de Topographia do Dr. Lucio Rodrigues. São Paulo: EPUSP, 1923.

RÜEGER, Jean M. Eletronic Distance Measurement: an introduction. Berlim: Springer-Verlag, 1990.

SANTOS, Paulo Marques dos. O Instituto Astronômico e Geofísico da USP: In: MATSUURA, Oscar T. (organizador). História da Astronomia no Brasil. v. 1. Recife: Cepe, 2014.

SCHERER, Michael; LERMA, José Luis. From the conventional Total Station to the Prospective Image Assisted Photogrammetric Scanning Total Station: Comprehensive Review. Journal of Surveying Engineering. v. 135, n. 4, p. 173-178, 2009. DOI.: 10106.10733.94532.00913.54173

SILVA, Irineu da. El Futuro de la Educación em Geomática para la Ingeniería Civil. CONCENCIÓN Y FERIA INTERNACIONAL INFORMÁTICA, XVI, 2016, Havana, Cuba. Concención y Feria Internacional Informática 2016, XVI. Havana, Cuba. Anais... Havana, Cuba. 14-18 mar., 2016.

SILVA, Irineu da. Geomatics Applied to Civil Engineering State of the Art. In: GHOSH, Jayanta Kumar; SILVA, Irineu da. Applications of Geomatics in Civil Engineering - Select Proceedings of ICGCE 
2018. Singapore: Springer Nature, 2020. DOI.: 10100.79789 .81137 .0670

SLADE. Giles. Made to Break: technology and obsolescence in America. Cambridge: Harvard University Press, 2006.

SOUSA, Gisela Mangabeira de; et al. O uso do SPRING como ferramenta de aprendizagem de Geoprocessamento. JORNADA DE EDUCAÇÃO EM SENSORIAMENTO REMOTO NO ÂMBITO DO MERCOSUL. IV, 2004, São Leopoldo, RS. Anais... São José dos Campos, SP: INPE, 11-13 ago., 2004. Disponível em: <http://www3.inpe.br/unidades/cep/atividadescep/jornada/programa/t-8_trab_30.pdf>. Acesso em: 24 jul. 2020.

SOUSA, Marcos Timóteo Rodrigues de; ROSAS, Celbo Antonio Fonseca. O Uso do Teodolito Mecânico no Ensino de Topografia: As formas "artesanais" de coleta de dados frente as novas tecnologias de precisão. Ciência Geográfica. v. 23, n. 1, p. 309-315, 2019.

SOUZA, Antonio Francisco de Paula. Elementos de Taqueometria: cleps, descrição e uso prático deste instrumento. São Paulo: [s.n.], 1895.

WASSERMANN, E. F. The Invar Problem. Journal of Magnetism and Magnetic Materials. v. 100, n. 1-3, p. 346, 362, 1991. DOI.: 10101.60304.88539.19082.8-X

WOLF, Paul R. Surveying and Mapping: history, current status, and future projections. Journal of Surveying Engineering. v. 128, n. 3, p. 79-107, 2002. DOI.: 10106.10733.94532.00212.8379

\section{Biografia dos autores}

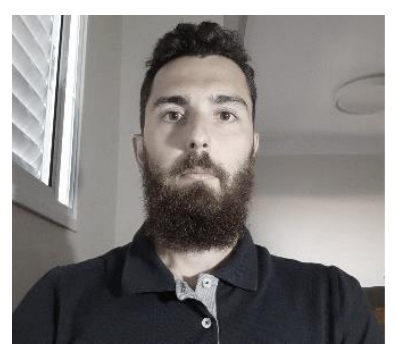

Jhonnes Alberto Vaz, natural de São Bernardo do Campo - SP, 1987. Engenheiro Cartógrafo formado pela Universidade do Estado do Rio de Janeiro, Mestre em Educação pela Universidade Católica de Santos e discente de doutorado do Programa de Pós-Graduação em Engenharia de Transportes (PPGET) da Escola Politécnica da Universidade de São Paulo. Docente na Universidade Católica de Santos. Interesse em Geodésia, GNSS e Educação em Engenharia.

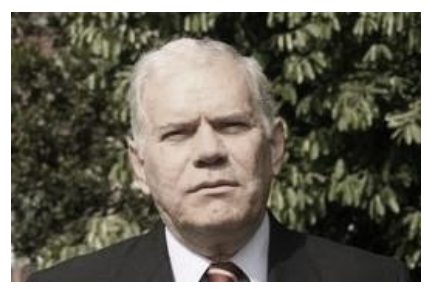

Jorge Pimentel Cintra, Professor Titular - Escola Politécnica e Museu Paulista da Universidade de São Paulo (USP).

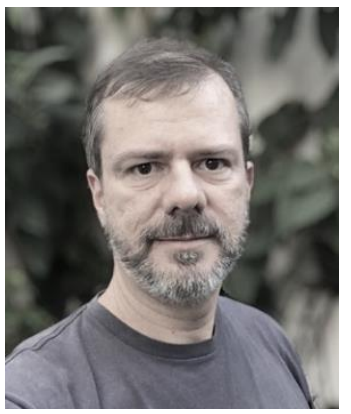

Flávio G Vaz de Almeida, natural de São Paulo - Capital, 1966. Físico (USP), Mestre em Eng. Elétrica/Telecomunicações, doutor em Eng. Transportes pela Escola Politécnica da USP (EPUSP) e doutor pela Univ. Paul Sabatier - TLSIII França. Pós-doutorado em Sistemas Logísticos EPUSP. Interesse em GPS/GNSS, Geodesia, estimativa emissões de GEE.

Esta obra está licenciada com uma Licença Creative Commons Atribuição 4.0 Internacional - CC BY. Esta licença permite que outros distribuam, remixem, adaptem e criem a partir do seu trabalho, mesmo para fins comerciais, desde que lhe atribuam o devido crédito pela criação original. 